\title{
The influence of pallets on the behaviour and design of steel drive-in storage racks - Part II Design
}

\author{
B.P. Gilbert \\ Griffith School of Engineering, Griffith University, Australia
}

L.H. Teh

School of Civil, Mining and Environmental Engineering, University of Wollongong, Australia

\author{
R.X. Badet \\ Griffith School of Engineering, Griffith University, Australia
}

K.J.R. Rasmussen

School of Civil Engineering, The University of Sydney, Australia

\begin{abstract}
This paper analyses the influence of the horizontal restraints provided by pallets on the ultimate capacity of drive-in racks. The paper is based on the assumption that one can accurately determine the coefficient of friction between the rail beams and the pallets or can design a device that restrains the pallets from sliding on the rail beams. Thirty-six drive-in racks representing the global sale of an Australian manufacturer over three years are analysed for all possible loading scenarios. For the sake of computational efficiency, the simple 2D model introduced in the companion paper is used for the study. The load case(s) governing the structural design is(are) also clarified and the friction coefficient or strength of a restraining device required to prevent the pallets from sliding is determined.
\end{abstract}

\section{INTRODUCTION}

This paper analyses the influence of the horizontal restraints provided by pallets on the ultimate capacity of drive-in racks. As introduced in the companion paper (Gilbert et al., 2013a), by acting as horizontal braces between adjacent uprights, pallets significantly influence the structural behaviour of drive-in racks and must be considered in order to accurately capture the 3D behaviour of this type of structure.

However, due to the uncertainty concerning the friction between the pallet bases and the rail beams, drive-in racks are currently designed without considering this bracing effects. If a device can prevent the pallets from sliding on the rail beams or if the coefficient of friction between the pallet bases and the rail beams can be reliably determined, the horizontal bracing effect provided by the pallets could be fully exploited in the design.

The current paper analyses the influence of the horizontal bracing effect of pallets on the design of steel drive-in racks in the down-aisle direction only. As mentioned in the companion paper (Gilbert et al., 2013a), due to the upright frames, pallets are not believed to influence the behaviour of the racks in the cross-aisle direction. It should also be noted that the friction between pallet bases and the rail beams would prevent the pallets from dropping through on account of the upright bowing deformations. As such, the serviceability check against upright bowing deformations is not considered in this paper.

Thirty six drive-in racks representing the global sale of an Australian manufacturer over three years are then analysed using the improved 2D single model introduced in the companion paper (Gilbert et al., 2013a) under all possible loading scenarios, alternately considering and ignoring the pallet bracing restraints. This paper evaluates the influence of pallet bracing restraints on the ultimate capacity of steel drive-in racks in the down-aisle direction, clarifies the loading scenario(s) governing the design and determines the friction coefficient or the strength of a restraining device required to prevent the pallets from sliding.

\section{PARAMETRIC STUDIES}

Thirty-six rack configurations, representing the global sale of an Australian manufacturer over three years and designed using industry practice (Dematic, 2006), are analysed using the improved single upright models introduced in the companion paper (Gilbert et al., 2013a). The racks are considered to be 4 pallets deep, with rail beams equally spaced apart along the rack height. The uprights are referred to as "SD" for standard uprights and "RF" for rear flanged uprights, their widths range from $70 \mathrm{~mm}$ to $150 \mathrm{~mm}$ and their thicknesses from $1.2 \mathrm{~mm}$ to 2.4 $\mathrm{mm}$. Table 1 summarises the rack configurations including the rack height, design pallet load, number of stories and upright type. More details can be found in (Gilbert, 2010, Gilbert et al., 2013b). 
Table 1: Rack configurations

\begin{tabular}{|c|c|c|c|c|c|c|}
\hline \multirow[b]{2}{*}{$\begin{array}{c}\text { Rack } \\
n^{\circ}\end{array}$} & \multirow[b]{2}{*}{$\begin{array}{c}\text { Height } \\
(\mathrm{mm})\end{array}$} & \multirow[b]{2}{*}{$\begin{array}{c}\mathrm{Nb} \\
\text { stories }\end{array}$} & \multirow[b]{2}{*}{$\begin{array}{c}\text { Design } \\
\text { pallet } \\
\text { load }(\mathrm{kg})\end{array}$} & \multicolumn{3}{|c|}{ Upright } \\
\hline & & & & Type & $\begin{array}{l}\text { Width } \\
\text { (mm) }\end{array}$ & $\begin{array}{l}\text { thk. } \\
(\mathrm{mm})\end{array}$ \\
\hline 1 & \multirow{4}{*}{3775} & 2 & 950 & SD & 70 & 1.2 \\
\hline 2 & & \multirow{2}{*}{3} & 950 & SD & 90 & 1.5 \\
\hline 3 & & & 1210 & $\mathrm{RF}$ & 90 & 1.2 \\
\hline 4 & & 4 & 690 & $\mathrm{RF}$ & 90 & 1.2 \\
\hline 5 & \multirow{8}{*}{5025} & \multirow{2}{*}{2} & 950 & SD & 90 & 1.2 \\
\hline 6 & & & 1210 & SD & 90 & 1.2 \\
\hline 7 & & \multirow{3}{*}{3} & 690 & $\mathrm{RF}$ & 90 & 1.2 \\
\hline 8 & & & 950 & $\mathrm{RF}$ & 90 & 1.2 \\
\hline 9 & & & 1210 & $\mathrm{RF}$ & 90 & 1.5 \\
\hline 10 & & \multirow{3}{*}{4} & 950 & SD & 110 & 1.5 \\
\hline 11 & & & 1210 & $\mathrm{RF}$ & 110 & 1.5 \\
\hline 12 & & & 1470 & $\mathrm{RF}$ & 125 & 1.5 \\
\hline 13 & \multirow{11}{*}{6275} & 2 & 1470 & $\mathrm{RF}$ & 90 & 1.2 \\
\hline 14 & & \multirow{3}{*}{3} & 950 & $\mathrm{RF}$ & 90 & 1.5 \\
\hline 15 & & & 1210 & SD & 110 & 1.5 \\
\hline 16 & & & 1470 & $\mathrm{RF}$ & 110 & 1.5 \\
\hline 17 & & \multirow{4}{*}{4} & 430 & SD & 90 & 1.5 \\
\hline 18 & & & 950 & SD & 110 & 1.2 \\
\hline 19 & & & 1210 & $\mathrm{RF}$ & 110 & 1.9 \\
\hline 20 & & & 1470 & $\mathrm{RF}$ & 125 & 1.5 \\
\hline 21 & & 5 & 950 & $\mathrm{RF}$ & 110 & 1.9 \\
\hline 22 & & \multirow{2}{*}{6} & 690 & $\mathrm{RF}$ & 110 & 1.5 \\
\hline 23 & & & 950 & $\mathrm{RF}$ & 125 & 1.5 \\
\hline 24 & \multirow{5}{*}{7525} & \multirow{2}{*}{3} & 1210 & SD & 110 & 1.5 \\
\hline 25 & & & 1470 & $\mathrm{RF}$ & 110 & 1.5 \\
\hline 26 & & \multirow{2}{*}{4} & 430 & $\mathrm{RF}$ & 90 & 1.2 \\
\hline 27 & & & 950 & $\mathrm{RF}$ & 110 & 1.9 \\
\hline 28 & & 5 & 950 & SD & 125 & 1.9 \\
\hline 29 & \multirow{8}{*}{8775} & 3 & 1210 & SD & 125 & 1.5 \\
\hline 30 & & \multirow{3}{*}{4} & 430 & $\mathrm{RF}$ & 90 & 1.7 \\
\hline 31 & & & 950 & SD & 125 & 1.9 \\
\hline 32 & & & 1210 & $\mathrm{RF}$ & 125 & 1.9 \\
\hline 33 & & \multirow{3}{*}{5} & 950 & SD & 150 & 1.9 \\
\hline 34 & & & 1210 & $\mathrm{RF}$ & 150 & 1.9 \\
\hline 35 & & & 1470 & $\mathrm{RF}$ & 150 & 2.4 \\
\hline 36 & & 6 & 950 & $\mathrm{RF}$ & 150 & 1.9 \\
\hline
\end{tabular}

Specifically, three different single upright models are considered and their member action-to-capacity ratios are used as a measure to quantify the influence of the pallet restraints on the design of drive-in racks:

- Model A considers the pallet bracing restraints and represents the Bay loading scenario A. The model is described in the companion paper (Gilbert et al., 2013a) in its Section 2.2.2.1 and illustrated in its Figure 6.

- Model B considers the pallet bracing restraints and represents the Bay loading scenario B. The model is described in the companion paper (Gilbert et al., 2013a) in Section 2.2.2.2 and illustrated in its Figure 7.

- Model C is based on the current industry practice of neglecting the pallet bracing restraints. The model is similar to Model A at the exception of
Step 4 in Section 2.2.2.1 of the companion paper (Gilbert et al., 2013a).

\subsection{Design parameters}

\subsubsection{Base plate to floor connection stiffness}

Base plates are generally bolted to the floor, and the strength and initial rotational stiffness of the base plate to floor connection depend on the axial load in the upright (Godley et al., 1998). Numerical investigations on the non-linear behaviour of a typical storage rack base plate assembly (Gilbert and Rasmussen, 2011) showed that (i) the connection strength is proportional to the upright width, (ii) in the presence of axial load in the upright, the initial rotational stiffness of the base plate to floor connection is proportional to the cube of the upright width and (iii) when no axial load is applied to the upright, the initial rotational stiffness is independent of the upright width.

The rules described above, combined with the test results in (Gilbert and Rasmussen, 2011) and applied to a $125 \mathrm{~mm}$ wide base plate assembly, are used in the following sections to determine the initial stiffness and strength of base plate to floor connections as functions of base plate widths. Detailed momentrotation curves used in the present work are given in Gilbert et al. (2013b).

\subsubsection{Out-of-plumb}

The main international racking specifications (AS 4084, 2012, EN 15512, 2009, RMI, 2008) consider the initial looseness in the member connections as well as the initial out-of-plumb as frame imperfections, which are generally accounted for in the design by means of horizontal forces $F_{\text {out-of-plumb }}$ applied at each rail beam elevation as,

$F_{\text {out-of-plumb }}=\alpha W$

where $\alpha$ is the out-of-plumb angle and $W$ is the vertical load applied to the upright by the pallets at the rail beam elevation. The out-of-plumb angle $\alpha$ is typically a function of the number of interconnected bays and the looseness in the portal beam to upright connections. A out-of-plumb angle of $0.0044 \mathrm{rad}$ (about 1/250) is used in the present work. See Gilbert et al. (2013b) for more details.

\subsubsection{Other parameters}

Other design parameters used in the present work, which correspond to some drive-in rack configurations currently commercialised in Australia, are given in Gilbert et al. (2013b). The height of the rack $H$, the number of pallet levels $N_{s}$ and the cross-sectional area of the upright $A_{u}$ depend on the studied rack characteristics and are given in Table 1 and Gilbert et al. (2013b). 


\subsection{Upright load cases}

According to the draft FEM specification for the design of drive-in racks (FEM 10.2.07, 2010), the load case involving the loading scenario depicted in Figure 5 in the companion paper (Gilbert et al., 2013a) and a fully loaded upright are usually "sufficient to consider the pattern load effects" for the Ultimate Limit State (ULS) design in the down-aisle direction. However, it is currently unclear if a different load case may govern the design. Moreover, in light of the horizontal bracing effect offered by the pallets, the load case involving the loading scenario depicted in in Figure 5 in the companion paper (Gilbert et al., 2013a) and a fully loaded upright may not always be sufficient for the ULS design of the upright.

Consequently, every possible load case is investigated in the present work for the 36 drive-in racks given in Table 1. Second-order geometric analyses are carried out using the general purpose FE software Strand7 (2010). The number of load cases analysed per rack is a function of the number rail beams and is equal to $4^{N s}$, where $N_{s}$ is the number of rail beam elevations.

\subsection{Ultimate capacity}

For each of the three rack models and each upright load case, the Australasian cold-formed steel structures standard AS/NZS 4600 (2005) is used to calculate the member action-to-capacity ratios of the critical upright. When second order-geometric analyses are used, members subjected to combined axial compression and bending must satisfy the ULS design check in Eq. (2),

$$
\frac{N^{*}}{\phi_{c} N_{c}}+\frac{M_{x}^{*}}{\phi_{b} M_{b x}}+\frac{M_{y}^{*}}{\phi_{b} M_{b y}} \leq 1
$$

where $N^{*}$ is the design axial compression load, and $M_{x} *$ and $M_{y} *$ are the design bending moments about the x- (cross-aisle) and y- (down-aisle) axes, respectively, $N_{c}$ is the nominal axial compression member capacity, $M_{b x}$ and $M_{b y}$ are the nominal member bending moment capacities about the $\mathrm{x}$ - and $\mathrm{y}$ - axes, respectively, $\phi_{c}$ and $\phi_{b}$ are reduction capacity factors for members in compression and bending, taken as 0.85 and 0.90 , respectively. As the present work is concerned with the design of drive-in racks in the down-aisle direction, the bending moment about the down-aisle axis is considered negligible and for the 2D single upright model, Eq. (2) becomes,

$$
\frac{N^{*}}{\phi_{c} N_{c}}+\frac{M_{x}^{*}}{\phi_{b} M_{b x}} \leq 1
$$

A load factor of 1.4 is used for the pallets to determine the design loads $N^{*}$ and bending moments $M_{x}{ }^{*}$. The self-weight of the rack is ignored.
The Direct Strength Method (Schafer, 2006) in Section 7 of the AS/NZS 4600 (2005) is used in the present work to calculate the nominal capacities $N_{c}$ and $M_{b x}$ of the upright. Specifically, the axial capacity in compression $N_{c}$ is defined as the lesser of the axial global, local and distortional nominal capacities $N_{c e}, N_{c l}$ and $N_{c d}$, respectively, as,

$$
N_{c}=\min \left(N_{c e}, N_{c l}, N_{c d}\right)
$$

and the nominal bending moment capacity $M_{b x}$ about the $\mathrm{x}$-axis of bending is defined as the lesser of the global, local and distortional nominal moment capacities $M_{b x e}, M_{b x l}, M_{b x d}$, respectively, as,

$M_{b x}=\min \left(M_{b x e}, M_{b x l}, M_{b x l}\right)$

Specifically, the global nominal capacity $M_{b x e}$ is a function of the bending moment distribution in the upright through the elastic buckling moment $M_{o}$,

$M_{o}=C_{b} A_{u} r_{o l} \sqrt{f_{o y} f_{o z}}$

where $C_{b}$ is a coefficient depending on moment distribution in the unbraced segment of the upright, $A_{u}$ is the gross cross-sectional area, $r_{o l}$ is the polar radius of gyration about the shear centre and $f_{o y}$ and $f_{o z}$ are the elastic buckling stresses for flexural buckling about the y-axes (perpendicular to the symmetry axis) and torsional buckling, respectively.

Detailled rules to determine $N_{c e}, N_{c l}, N_{c d}, M_{b x e}$, $M_{b x l}, M_{b x d}$ are given in AS/NZS 4600 (2005).

\subsubsection{Effective buckling lengths}

The Australian Standard AS 4084 (2012) recommends effective lengths $l_{e y}$ and $l_{e z}$ for buckling about the y- (down-aisle) and z- (torsional) axes equal to $h$ and 0.7 times $h$, respectively, where $h$ represents the upright frame bracing pitch, as shown in Figure 1. These values are adopted in the present work.

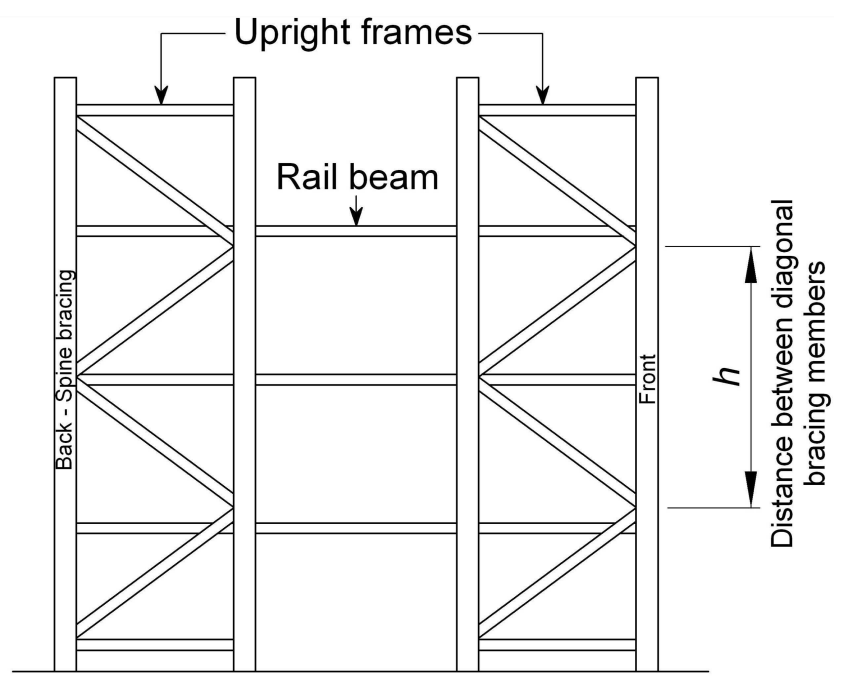

Figure 1: Frame bracing pitch h, unbraced segment

For each member of the simple upright model, the effective length $l_{e x}$ for buckling about the $\mathrm{x}$-axis (in 
the down-aisle plane) is calculated as (Teh and Gilbert, 2013),

$l_{e x}=\pi \sqrt{\frac{E I_{x}}{N_{c r b}}}$

where $I_{x}$ is the second moment of area about the $x$ axis, and $N_{c r b}$ is the elastic buckling load of the upright determined from a rational frame buckling analysis (Teh and Gilbert, 2013).

\section{RESULTS}

\subsection{Effects of pallet restraint}

In this study, two values for the frame bracing pitch $h$, being $1,500 \mathrm{~mm}$ and $2,000 \mathrm{~mm}$, are considered.

\subsubsection{Frame bracing pitch $h=1,500 \mathrm{~mm}$}

Figure 2 plots the ratios of the maximum member action-to-capacity ratio of Model $\mathrm{C}$ (current industry practice) to that of Model A, and to that of Model B, for the 36 racks given in Table 1 having a frame bracing pitch $h$ of $1500 \mathrm{~mm}$. Detailed results can be found in Gilbert et al. (2013b). A ratio greater than 1.0 in Figure 2 indicates that the current industry practice results in uneconomical designs.

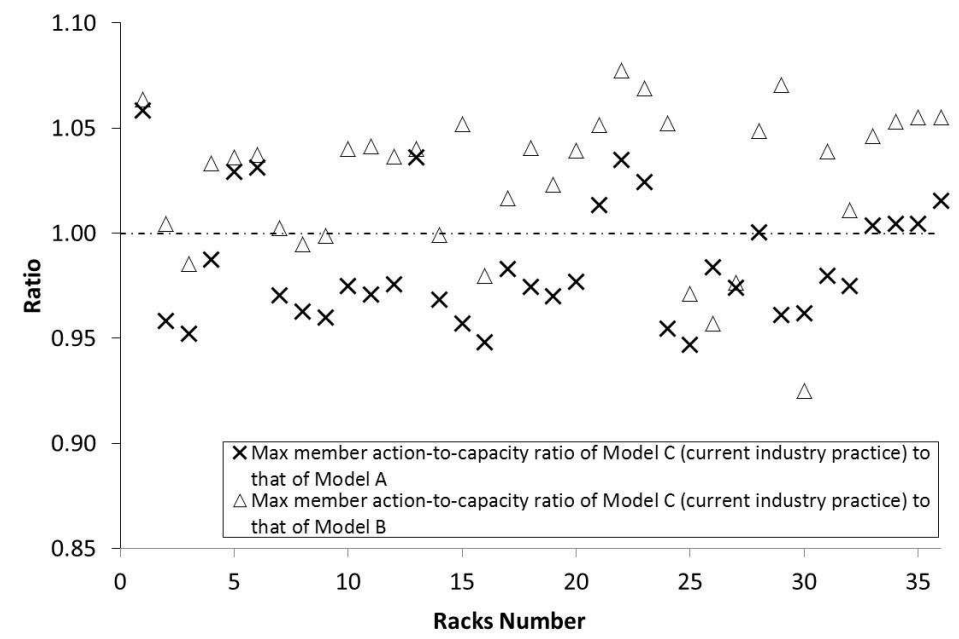

Figure 2: Influence of the horizontal pallet restraint on the action-to-capacity ratio for $h=1,500 \mathrm{~mm}$

Figure 2 shows that for 12 racks out of 36, incorporating the horizontal restraining effect provided by the pallets would provide more economical designs than the current industry practice, with a decrease in the member action-to-capacity ratio of up to $6 \%$ (Rack 1). On average for the 12 racks, the decrease is $2 \%$.

For the remaining 24 racks, ignoring the pallet restraints would lead to less conservative designs, with a increase in the member action-to-capacity ratio of up to $7 \%$ (Rack 30). On average for the 24 racks, ignoring the pallet restraints increases the design capacity by $3 \%$. This counterintuitive result is mainly due to the effect of the pallet restraints on the design bending moment of the upright under the critical load case. Figure 3 shows the bending moment distribution in the upright for Models A and C, and the coefficient $C_{b}$ in Eq. (6), under the critical load case of Rack 25. It can be seen that ignoring the pallet restraints leads to a design bending moment that is $12 \%$ less than when considering same, but with similar $C_{b}$ coefficient.

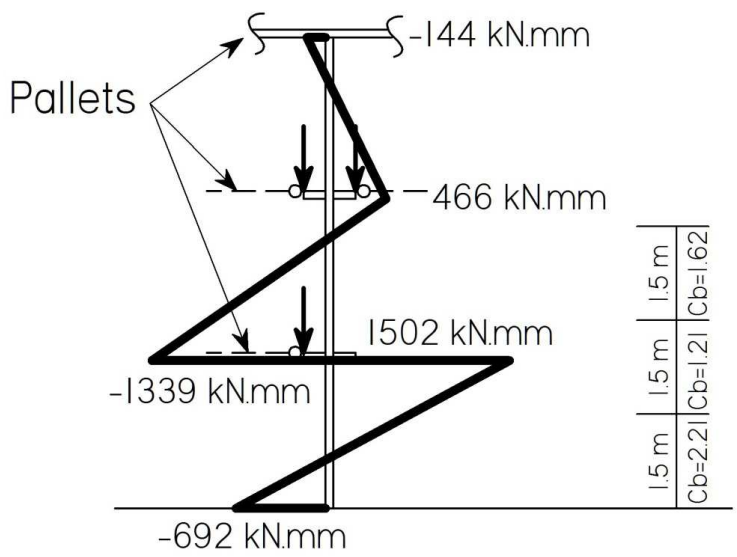

(a)

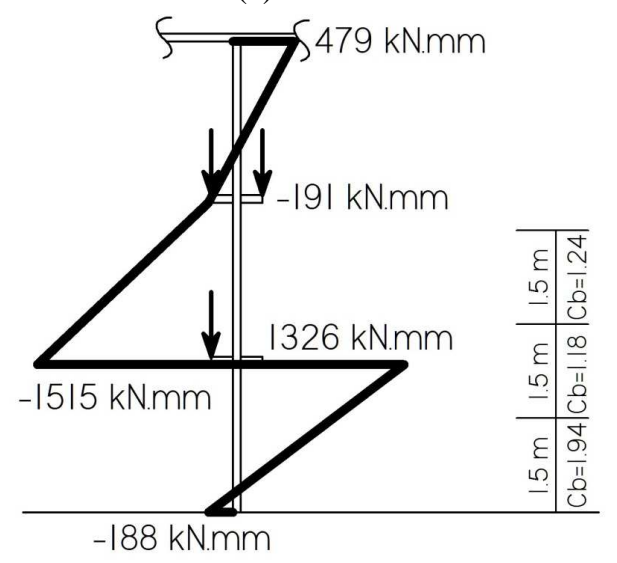

(b)

Figure 3: Bending moment distribution for the critical load case for rack 25 for (a) Model A and (b) Model C

Table 2 summarises the average maximum member action-to-capacity ratios given in Figure 2.

Table 2: Ratio of the maximum member action-to-capacity ratios of Model C(current industry practice) to the Models A and B

\begin{tabular}{c|cc|cc}
\multirow{2}{*}{$\mathrm{h}(\mathrm{mm})$} & \multicolumn{2}{|c|}{$\begin{array}{c}\text { Model C (current prac- } \\
\text { tice) / Model A }\end{array}$} & \multicolumn{2}{c}{$\begin{array}{c}\text { Model C (current prac- } \\
\text { tice) / Model B }\end{array}$} \\
\cline { 2 - 5 } & $\begin{array}{c}\text { Average } \\
\text { ratio }\end{array}$ & CoV & $\begin{array}{c}\text { Average } \\
\text { ratio }\end{array}$ & CoV \\
\hline $1,500 \mathrm{~mm}$ & 0.99 & 0.029 & 1.03 & 0.034 \\
$2,000 \mathrm{~mm}$ & 0.99 & 0.026 & 1.04 & 0.016
\end{tabular}

\subsubsection{Frame bracing pitch $h=2,000 \mathrm{~mm}$}

Figure 4 plots the ratios of the maximum member action-to-capacity ratio of Model $\mathrm{C}$ (current industry practice) to that of Model A, and to that of Model B, for the 36 racks given in Table 1 having a frame bracing pitch $h$ of $2000 \mathrm{~mm}$. Detailed results can be found in Gilbert et al. (2013b).

Similar conclusions to those in Section 3.1.1 can be drawn. Results show that for 11 racks out of 36 , 
considering the horizontal restraining effect provided by the pallets would provide more economical designs than the current industry practice, with a decrease in the member action-to- capacity ratio of up to $5 \%$ (Rack 1) and an average decrease of $2 \%$. For the remaining 25 racks, ignoring the pallet restraints would lead to less conservative designs, with a maximum increase in the member action-to-capacity ratio of 5\% (Rack 25) and an average increase of $3 \%$. Table 2 summarises the average maximum member action-to-capacity ratios given in Figure 4.

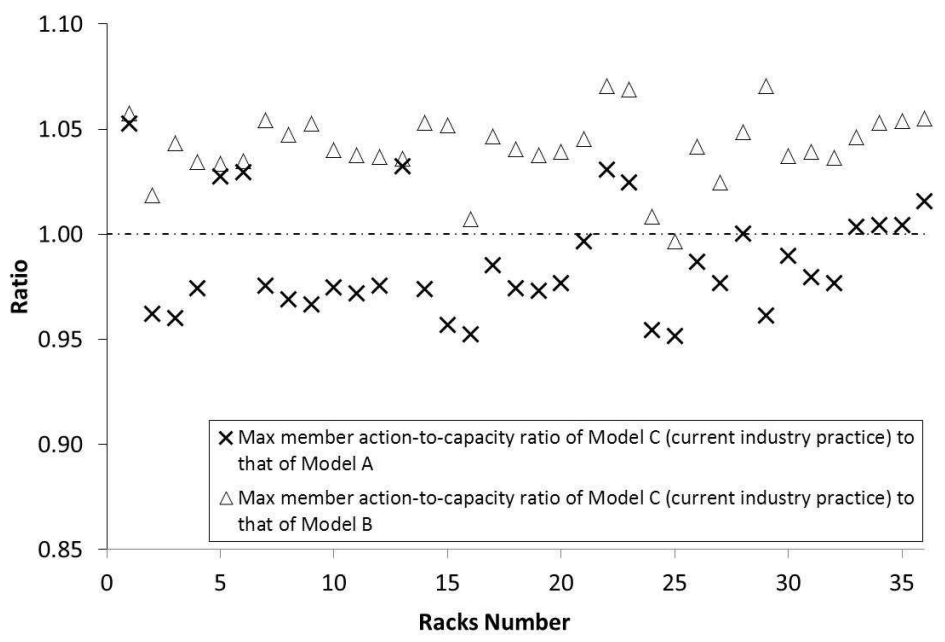

Figure 4: Influence of the horizontal pallet restraint on the action-to-capacity ratio for $\mathrm{h}=2,000 \mathrm{~mm}$

\subsubsection{Critical load cases}

When the pallet restraints are considered in the analysis (Models A and B), the load case involving the loading scenario shown in Figure 5 in the companion paper (Gilbert et al., 2013a), which corresponds to a fully loaded rack except for one compartment at the first rail beam elevation, is found to govern the design in general. However, for the 4-storey drive-in racks number 26 and 30, the load case shown in Figure 5 (a) is found to provide an action-to-capacity ratio up to $13 \%$ higher than the load case involving the loading scenario shown in Figure 5 in the companion paper (Gilbert et al., 2013a). Despite a lower axial load incurred in the critical upright, the loading scenario induces a buckling length $l_{e x}$ about twice that for the loading scenario shown in Figure 13, and therefore leads to a reduced axial capacity.

When the pallet restraints are ignored in the analysis, the load case involving the loading scenario shown in Figure 5 in the companion paper (Gilbert et al., 2013a) is also found to generally govern the design. However, the load cases shown in Figure 5 (b) for the 4-storey drive-in rack number 4, Figure 5 (c) for the 5-storey rack number 21 and Figure 5 (d) for the 6-storey drive-in racks number 21, 22 and 36 govern the design with an action-to-capacity ratio $2 \%, 3 \%$ and $4.5 \%$ higher that the loading scenario shown in Figure 5 in the companion paper (Gilbert et al., 2013a), respectively.

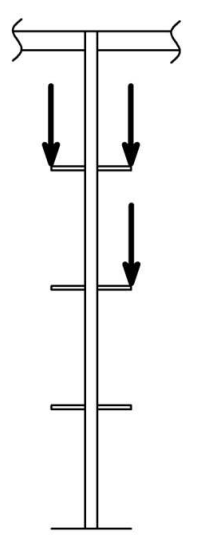

(a)

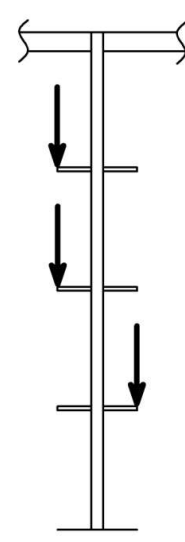

(b)

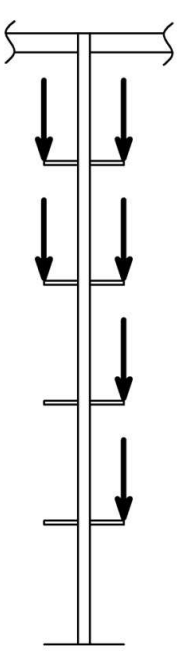

(c)

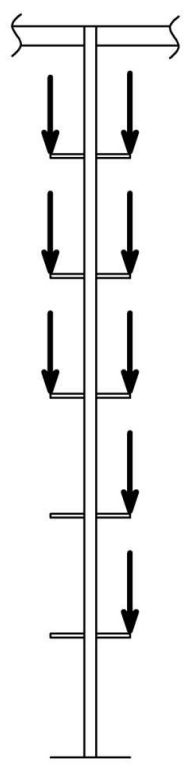

(d)
Figure 5: Specific load cases governing the design

In view of the above results, for ULS design ignoring pallet bracing effects, limiting the analysis to the load case involving the loading scenario shown in Figure 5 in the companion paper (Gilbert et al., 2013a) and a fully loaded rack, would only induce a limited error in the action-to-capacity ratio and may be considered to be "sufficient for considering the pattern load effects".

\subsection{Friction coefficient analysis}

The minimum friction coefficient $\mu$ needed to prevent the pallets from sliding on the rail beams is investigated herein for Model A. The friction forces $S_{f}$ developed between the pallets and the rail beams are extracted from the horizontal reactions at each loaded rail beam elevation of the single upright model. The friction coefficient $\mu$ is then calculated as,

$\mu=\frac{S_{f}}{W}$

where $W$ is the axial load applied by the pallets to the upright at the rail beam elevation.

Figure 6 shows the minimum friction coefficient needed to prevent sliding of the pallets found for all loading cases and for the 36 drive-in racks in Table 1. All values in Figure 6 are less than the design static friction coefficient of 0.439 recommended by Hua and Rasmussen (2010) (see companion paper), indicating that, under normal operating conditions, sliding is unlikely to occur between the pallets and the rail beams, and that pallet bracing restraints could be considered in the design of drive-in racks. Moreover, the minimum friction coefficient $\mu$ is dependent on the number of stories (or rail beam elevations), as seen in Figure 6. The more the stories, the more likely the pallets are to slide. Results show that, for a given number of stories, the minimum coefficient of 
friction required to avoid sliding of the pallets decreases somewhat linearly with the height of the rack.

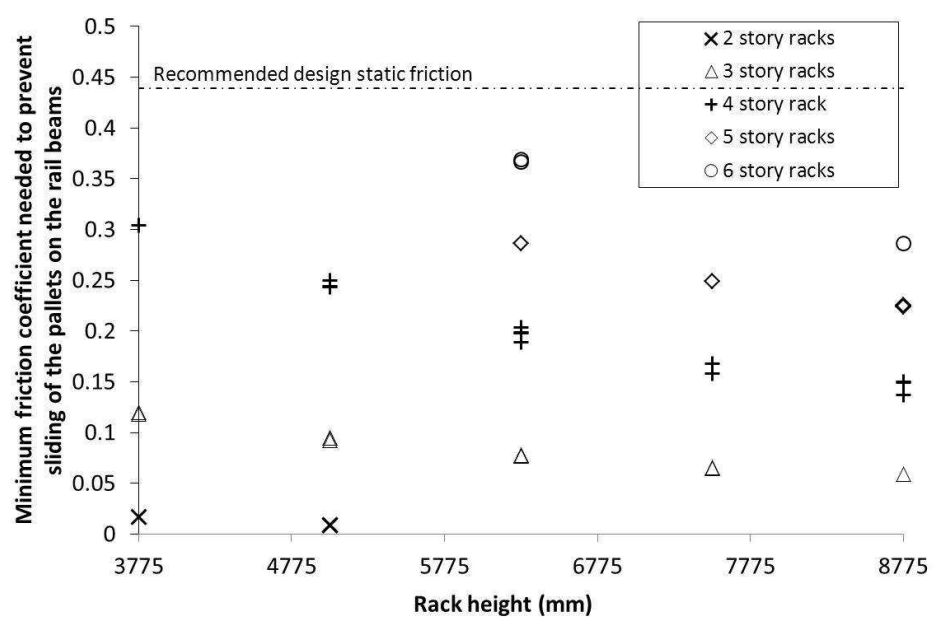

Figure 6: Minimum friction coefficient $\mu$ needed to prevent pallets from sliding

\section{CONCLUSIONS}

This paper analyses the influence of horizontal bracing restraints provided by the pallets on the design of steel drive-in racks. Using the improved single upright model presented in the companion paper, analyses were run for 36 drive-in rack configurations. All possible loading cases were analysed. Results showed that ignoring the pallet bracing effects in design, as in the current industry practice, usually leads to a less conservative design with an action-tocapacity ratio for the critical upright being reduced in the order of $4 \%$.

The load case involving a fully loaded rack except for one compartment at the first rail beam elevation was found to govern the Ultimate Limit State design of most racks. However, loading scenarios inducing the maximum bending moments were also found to govern the design of some drive-in racks having 4 to 6 storeys, with action-to-capacity ratios up to $5 \%$ greater than the previous load case when pallets are ignored.

Results show that under normal operating conditions, the friction coefficient between the pallets and the rail beams is sufficient to prevent sliding of the pallets, and therefore pallets could be considered in the design of drive-in racks.

\section{REFERENCES}

AS 4084 2012. Steel storage racking. Standards Australia, Sydney, Australia.

AS/NZS 4600 2005. Cold-formed steel structures. Standards Australia, Sydney, Australia.

DEMATIC 2006. RAD - User manual, Sydney, Australia, Dematic, Pty. Ltd.
EN 15512 2009. Steel static storage systems - Adjustable pallet racking systems - Principles for structural design. European Committee for Standardization (CEN), Brussels, Belgium.

FEM 10.2.07 2010. Version 0.12 - Draft - The Design of 'Drive-in' and 'Drive-through' pallet racking. Federation Europeenne de la Manutention, Brussels, Belgium.

GILBERT, B. P. 2010. The behaviour of steel drive-in racks under static and forklift truck impact forces. $\mathrm{PhD} \mathrm{PhD}$, School of Civil Engineering, The University of Sydney.

GILBERT, B. P. \& RASMUSSEN, K. J. R. 2011. Determination of the base plate stiffness and strength of steel storage racks. Journal of Constructional Steel Research, 67, 1031-1041.

GILBERT, B. P., TEH, L. H., BADET, R. X. \& RASMUSSEN, K. J. R. The influence of pallets on the behaviour and design of drive-in steel storage racks - Part I Behaviour. Fifth International Conference on Structural Engineering, Mechanics and Computation, 2013a Cape Town, South Africa.

GILBERT, B. P., TEH, L. H., BADET, R. X. \& RASMUSSEN, K. J. R. 2013b. Determination of the influence of the pallets on the design of drive-in steel storage racks. Research Report CIEM/2013/R04. Centre for Infrastructure Engineering and Management, Griffith University, Australia.

GODLEY, M. H. R., BEALE, R. G. \& FENG, X. Rotational stiffness of semi-rigid baseplates. In: Yu, W.W. \& Laboule, R.A., eds. 14th International Specialty Conference on ColdFormed Steel Structures, October, 15-16 1998 St Louis, Missouri, U.S.A., 323-335.

HUA, V. \& RASMUSSEN, K. J. R. 2010. Static friction coefficient between pallets and beam rails and pallet shear stiffness tests. Research Report 914. School of Civil Engineering, The University of Sydney, Australia.

RMI 2008. Specification for the design, testing and utilization of industrial steel storage racks. Rack Manufacturers Institute, Charlotte, U.S.A.

SCHAFER, B. W. Designing cold-formed steel using the direct strength method. In: Laboule, R.A. \& Yu, W.W., eds. 18th International Specialty Conference on Cold-Formed Steel Structures 29-27 October 2006 Orlando, Florida. 475-490.

STRAND7 2010. Using Strand7 - User manual - Release 2.4.4, Sydney, Australia, G+D Computing Pty Ltd.

TEH, L. H. \& GILBERT, B. P. 2013. Second-order elastic analysis based design of drive-in racks. ASCE Journal of Structural Engineering (in preparation). 